\title{
EXPRESSING ORGANIZATIONAL DISSENT: THE ROLE OF ETHICAL IDEOLOGY AND CORPORATE ETHICAL VALUES
}

\author{
Sean Valentine \\ University of Wyoming \\ Laramie, WY \\ Kimberly Young \\ Citation-Mabry Company \\ Beaumont, TX \\ Lorissa Bailey \\ Life Resource Community Mental Health Center \\ Beaumont, TX \\ Naser Barhoum \\ Lamar University \\ Beaumont, TX \\ Stacy LaBure \\ Roche Labs, Inc. \\ Beaumont, TX \\ Natasha Glover \\ Federal Prison Industries \\ Beaumont, TX \\ Peter Isaac \\ East Texas Pathology Laboratory \\ Beaumont, TX
}

\begin{abstract}
Using a sample of 101 employees from a community-based health care agency in the southern U.S., we empirically examined the relationships between organizational dissent and idealism, relativism, and corporate ethical values. The results indicated that idealism and dissent were negatively related, relativism and dissent were unrelated, and corporate ethical values and dissent were positively associated. The findings suggest that both individual and organizational factors should be noted when assessing dissent.
\end{abstract}

Individual judgments concerning the ethics or morality of specific actions are typically the focus of ethical decision-making studies. Models produced 
in these studies generally propose a causal linkage between ethical judgments regarding an action and an individual's behavioral intentions (Barnett, Bass \& Brown, 1994; Dubinsky \& Loken, 1989; Hunt \& Vitell, 1986; Jones, 1991) or an individual's actual behavior with regard to ethical issues (Barnett et al., 1994; Trevino, 1986). Forsyth (1992) states that judgments are influenced by personal moral philosophies such as idealism, which relates to the concern for others, and relativism, which refers to the rejection of common moral rules. In addition to personal moral philosophies, contextual factors such as rewards, rules, and codes also influence ethical decisions (Trevino, Butterfield \& McCabe, 1998). Corporate ethical values, which are comprised of many contextual factors, establish ethical standards that influence individual choices (Conner \& Becker, 1975; Hunt, Wood \& Chonko, 1989; Jansen \& Von Gilnow, 1985), and they have been theorized to influence individual actions in organizations as well (Hunt et al., 1989; Yankelovich, 1971).

Dissent, which is a form of individual behavior, has also received considerable attention by both practitioners and scholars in the past two decades (Near, Baucus \& Miceli, 1993). Dissent is an individual's expression of disagreement with an organization's practices, policies and operations (Kassing, 1998), and serves as a form of corrective employee feedback (Hegstrom, 1995), which is necessary for organizational success (Kassing, 1998; Thompkins, 1977). Since personal moral philosophies and organizational ethical values are theoretically linked to ethical judgments, the purpose of this study is to investigate the role of dissent in ethical issues by examining how idealism, relativism, and corporate ethical values influence the expression of dissent. Figure 1 outlines the study's framework and intent.

\section{Organizational Dissent}

Kassing (1998) defines dissent as a multi-step process that involves feeling apart from onc's organization and is driven by (1) the recognition of wrongdoing, (2) the need for intervention, (3) perceived responsibility, and (4) the screening of alternatives. Dissent is essentially an individual's expression of disagreement with an organization's practices, policies, and operations (Kassing, 1998). The majority of the research on dissent has failed to consider the entire range of dissenting behavior, with most studies focusing on whistle-blowing (Dozier \& Miceli, 1985), which is an extreme case of dissent (Kassing, 1998). Whistle-blowing involves the disclosure of unethical practices to people both inside and outside of the organization who possess the ability to initiate change (Miceli \& Near, 1985; Redding, 1985; Stewart, 1980). Although such actions may present a threat to the formal chain-of-command (Stone, 1975), whistleblowing can improve long-term organizational effectiveness (Brief \& Motowidlow, 1986). 
Figure 1

An Ethics Framework of Organizational Dissent

ETHICAL

IDEOLOGIES

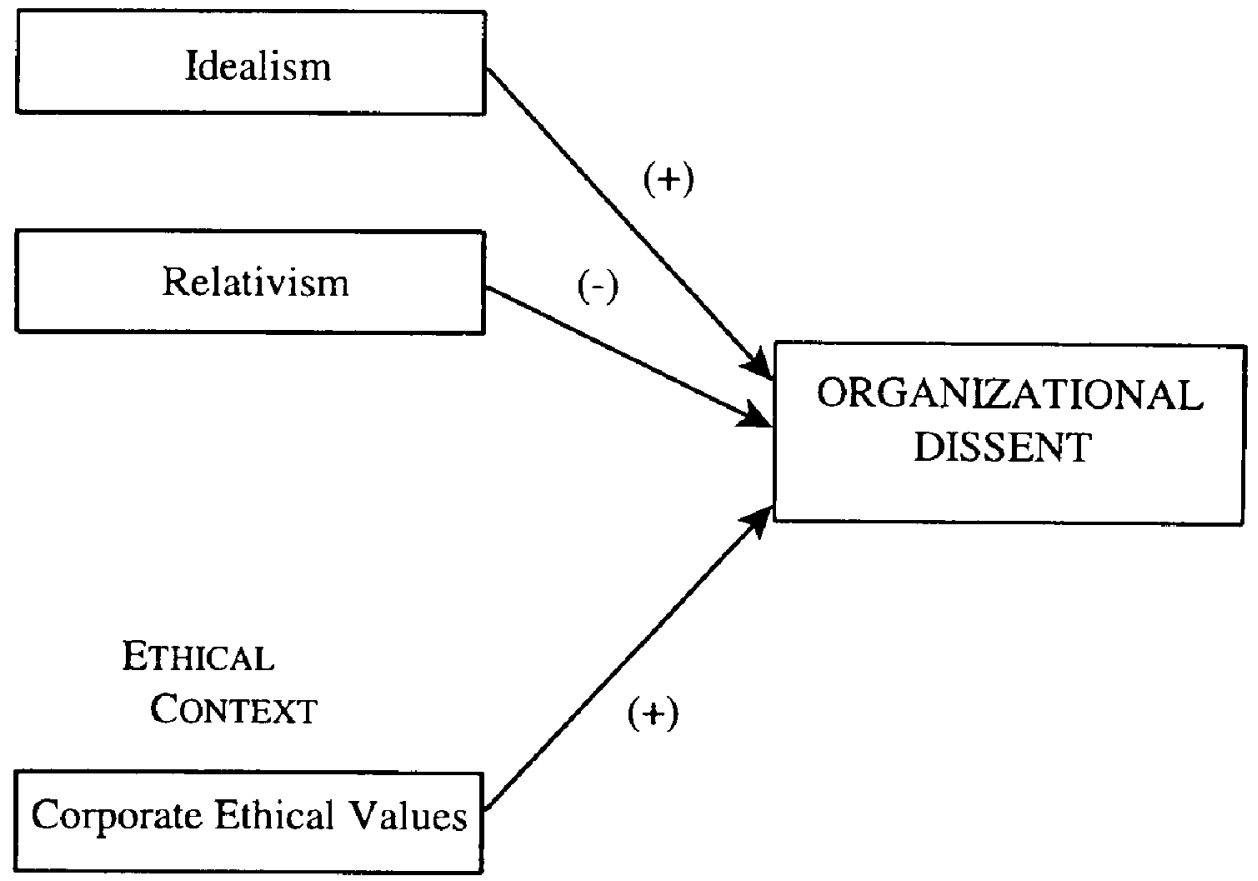

Dissent is broader than whistle-blowing in terms of the audiences to whom disagreements are expressed (Kassing, 1998). It is considered to be an antecedent to whistle-blowing because whistle-blowers tend to express their disagreements within the organizations initially and only turn to public, external sources when organizations are unresponsive to their concerns (Stewart, 1980). Kassing (1998) argues that many employees assess available strategies for expressing dissent in response to individual, relational and organizational influences, and that they actually express dissent after considering whether they will be perceived as adversarial or constructive and the likelihood that they will be retaliated against for expressing dissent.

Kassing (1998) also suggests that individuals use articulated, latent, and displaced methods for expressing dissent. Articulated dissent involves expressing concerns directly and openly with management, supervisors, and corporate officers who can effectively adjust the wrongdoing within organizations and occurs when employees believe that they will be perceived as constructive and that their dissent will not lead to retaliation. Latent dissent involves expressing dissent about personal-advantage issues to people who are captive or influential, 
and occurs when employees believe that they will be perceived as adversarial but also feel they have some safeguard against retaliation. And finally, displaced dissent involves expressing dissent to external audiences (like spouses/partners, family members, and non-work friends) and/or to ineffectual internal audience (like fellow coworkers who have no ability to address the dissent concern directly). Displaced dissenters believe that their behavior is perceived as adversarial and will be answered with retaliation (Kassing, 1998).

\section{Ethical Ideology}

Personal moral philosophies have been linked to ethical decisions (Barnett, Bass \& Brown, 1996, 1994; Forsyth, 1992, 1980; Hunt \& Vasquez-Parraga, 1993; Hunt \& Vitell 1993, 1986; Schlenker \& Forsyth, 1977). A personal moral philosophy is defined as a set of beliefs, attitudes, and values that provide a framework for considering ethical dilemmas (Barnett et al., 1994), and they offer guidance to individuals as they make ethical judgments (Forsyth \& Nye, 1990). More specifically, Forsyth (1992) concluded that moral philosophies might influence judgments of certain business practices and decisions to engage in those practices. There are many individual personal philosophies (Forsyth, 1992), but the ethics literature focuses particularly on relativism and idealism.

A highly relativistic individual espouses a personal moral philosophy based on skepticism, which assumes "that it is impossible to develop or follow universal principles" when making decisions (Barnett et al., 1994, p. 471). Highly relativistic individuals feel that moral actions depend on the nature of the situation and the individuals involved so that when judging others, they weigh the circumstances more than the ethical principle that was violated. Thus, individuals scoring high in relativism tend to reject the notion of an overriding moral code (Barnett et al., 1994; Vitcll, Rallapalli \& Singhapakdi, 1993), and individuals scoring low in relativism support only those moral actions that are founded in moral principle, norms, or law (Forsyth, 1992). Idealism describes a concern for others, and highly idealistic individuals believe that morally "right" behavior leads to good or positive consequences (Vitell et al., 1993). A highly idealistic individual feels that harming others is always avoidable and will not act in a manner that leads to negative consequences. A low idealistic individual believes that harm will sometimes be necessary to produce good (Forsyth, 1992, 1980; Schlenker \& Forsyth, 1977). Consequently, Forsyth (1980) describes a model of personal moral philosophy that focus on both principles and consequences.

Empirical studies generally suggest that individuals who subscribe to different ethical ideologies vary in their judgments of ethical issues (Barnett, Bass \& Brown, 1998; Barnetl et al., 1994; Forsyth, 1981; Forsyth \& Pope, 1984). Forsyth (1980) concluded that students scoring high in idealism and low in relativism tended to judge ethical issues harsher than other students. Barnett et al. (1994) examined how business students' ethical ideologies affected their 
ethical judgments in various business situations. Results indicated that highly idealistic individuals' judgments were harsher compared to those from others, while individuals classified as low idealists and high relativists were the most lenient in their ethical judgments. And finally, Barnett et al. (1998) concluded that individuals classified as highly idealistic and non-relativistic judged ethical issues more harshly than other individuals using a national sample of marketing professionals (Barnett et al., 1998).

The relationship between ethical ideology and intention to report a peer's wrongdoing has been explored (Barnett et al., 1996). Peer reporting involves telling an authority figure about a person's unethical actions and is considered a specific type of whistle-blowing (Trevino \& Victor, 1992). Barnett et al. (1996) found that individuals who were classified as highly idealistic and low relativistic were more likely to consider reporting a peer's cheating as ethical. Individuals who believed reporting a peer's cheating was ethical were more likely to say they would report a peer's cheating. Since the theory of reasoned action suggests that individuals' attitudes or judgments influence their behavioral intentions, and that behavioral intentions are predictive of behavior (Ajzen \& Fishbein, 1980), there is reason to believe that ethical ideology may also influence dissent.

Highly idealistic individuals are generally concerned with the welfare of others. Trevino and Victor (1992) found that these individuals are more likely to perceive peer reporting as ethical when the wrongdoing has the potential to harm the group as a whole. Forsyth and Nye (1990) found that low relativistic individuals were less likely than high relativists to violate a social norm for personal gain. Similarly, Barnett et al. (1996) suggested that individuals scoring high in relativism may be more likely to excuse unethical behavior if it is self-beneficial, and therefore, be less likely to be a whistleblower than a low relativist. Based on the above discussion, the following hypotheses are presented:

\section{Hypothesis 1: Idealism will be positively related to organiza- tional dissent.}

\section{Hypothesis 2: Relativism will be negatively related to organi- zational dissent.}

\section{Corporate Ethical Values}

Liedtka (1991) indicated that people rather than organizations make decisions. However, organizations do have core values that represent the corporate principles and beliefs, and these values play an important role in individual decisions (Hunt et al., 1989; Liedtka, 1991; Schein, 1985; Selznick, 1957). Corporate values are a major facet of corporate culture (Hunt et al., 1989), which tends to define what is and is not appropriate behavior within an organization (Akaah, 1993; Akaah \& Riordan, 1990; Trevino 1986). Corporate ethical values are a 
composite of managers' ethical values and the formal and informal ethics policies of an organization, and they establish and maintain ethical standards by which individual choices are influenced (Conner \& Becker, 1975; Hunt et al., 1989; Jansen \& Von Glinow, 1985). According to Trevino and Youngblood (1990), such an ethical culture encourages ethical behavior through various formal and informal social networks.

Weaver, Trevino, and Cochran (1999) state that organizational ethical values can be defined through control theory and managerial choice theory. Control theory outlines the scope of the ethics program and its compliance structure, while managerial choice theory suggests that various environmental factors and the level of managerial commitment to ethics programs influence the characteristics of the program. Weaver et al. (1999) conclude that while control theory is instrumental in the formation of ethical programs, management and environmental factors influence the program's dimensions.

Trevino, Weaver, Gibson and Toffler (1999) emphasize that although control theory is important, a values-based approach for ethics programs ensures a stronger commitment to ethical behavior. Although it is important for employees to recognize ethical issues, it is even more imperative for them to act ethically. In addition, employees need to be comfortable enough with their supervisors to discuss ethical issues without the fear of punishment. With supervisory support, Trevino et al. (1999) note that companies can develop and successfully implement ethics programs.

Several U.S. corporations have implemented formal ethics programs, many of which have varying characteristics. Ethics programs typically include ethics codes, ethics committees, communications systems, ethics officers, training programs, and various disciplinary procedures. Although the amount of control over these programs varies by organization, they are generally developed to monitor ethical conduct and to punish those who do not abide by set standards. Weaver et al. (1999) refers to such programs as compliance+oriented. Alternatively, values-oriented ethics programs focus on the development of shared values that encourage ethical conduct.

Empirical efforts have generally highlighted a consistent relationship between organizational ethical values and ethical behavior. Gaertner (1991) found that a number of ethical climate dimensions influenced ethical decision-making indirectly. Trevino et al. (1998) concluded that various measures of ethical context were strongly associated with both individual behavior and commitment. Sims and Keenan (1998) concluded that external whistleblowing was influenced by both organization and individual characteristics. And finally, a number of studies (Conner \& Becker 1975; Haberstroh \& Gerwin, 1972; Hunt et al., 1989; Jansen \& Von Glinow, 1985; Trevino et al., 1998) have also indicated that there is a relationship between various types of corporate ethical programs and employee behavior. Based on previous empirical efforts, the following hypothesis is presented. 
Hypothesis 3: Corporate ethical values will be positively related to organizational dissent.

\section{Methods}

Data were obtained by means of a self-administered questionnaire distributed to approximately 250 employees employed at a community-based health care agency in the southern United States, and a sample of 101 respondents was obtained. The total survey count yielded an approximate response rate of $40 \%$. The questionnaire included the Ethical Position Questionnaire (EPQ), the Corporate Ethical Values Scale (CEV), the Organizational Dissent Scale (ODS), and various items that measured demographic and professional characteristics. Examples of scale items are provided in Appendix $A$.

Forsyth (1980) developed the EPQ to evaluate an individual's personal moral philosophy and to tap the degree to which an individual is relativistic, or regards universal moral principles, and the degree to which an individual is idealistic, or regards the consequences of actions. The EPQ is a 20-item, 9-point Likert-type scale ranging from 1 (strongly disagree) to 9 (strongly agree), and ten items measure relativism and ten items measure idealism (Barnett et al., 1994; Forsyth, 1980). The CEV scale developed by Hunt et al. (1989) is a five-item, seven-point Likert-type scale ranging from 1 (strongly disagree) to 7 (strongly agree). The scale measures individual perceptions of managerial behavior, concerns for ethical standards, and the extent to which ethical behavior is rewarded. The ODS was developed by Kassing (1998) and measures how employees express their concerns at work. The scale utilizes a five-point Likert-type scale ranging from 1 (strongly disagree) to 5 (strongly agree), and contains 20 items that measure various dimensions of dissent. Reliability analysis was conducted, and acceptable coefficient alphas for organizational dissent $(\alpha=.79)$, idealism $(\alpha=.77)$, relativism ( $\alpha=.81)$, and corporate ethical values $(\alpha=.88)$ were obtained.

\section{Results}

A summary of the sample characteristics is presented in Table 1. Approximately $77 \%$ of the respondents were female, and nearly $69 \%$ of the sample was comprised of Anglo-Americans. Over half of the respondents (60\%) were married, and $61 \%$ of the respondents had a Bachelor's degree or some college. The majority of the respondents $(73 \%)$ earned less than $\$ 30,000$ per year, and the total household income was less than $\$ 50,000$ for $61 \%$, between $\$ 50,000-80,000$ for $21 \%$ and over $\$ 80,000$ for $18 \%$. Thirty-seven percent of the respondents were professionals within the company, $21 \%$ were clerical, $17 \%$ were in management, and $14 \%$ were technical. 
Table 1

Characteristics of the Sample

\begin{tabular}{|c|c|c|c|c|}
\hline Variable & & Frequency & Valid \% & Cumulative $\%$ \\
\hline \multirow{3}{*}{ Sex } & Female & 71 & 77.2 & 77.2 \\
\hline & Male & 21 & 22.8 & 100.0 \\
\hline & Total & 92 & 100.0 & \\
\hline \multirow{5}{*}{$\begin{array}{l}\text { Marital } \\
\text { Status }\end{array}$} & Single & 23 & 24.5 & 24.5 \\
\hline & Married & 56 & 59.6 & 84.0 \\
\hline & Divorced & 15 & 16.0 & 100.0 \\
\hline & Widowed & 0 & .0 & \\
\hline & & Total & 94 & 100.0 \\
\hline \multirow{3}{*}{$\begin{array}{l}\text { Minority } \\
\text { Status }\end{array}$} & Anglo American & 60 & 68.2 & 68.2 \\
\hline & Minority & 28 & 31.8 & 100.0 \\
\hline & Total & 88 & 100.0 & \\
\hline \multirow{7}{*}{ Education } & Some H.S & 2 & 2.2 & 2.2 \\
\hline & H.S. Grad & 30 & 17.2 & 19.4 \\
\hline & Some College & 15 & 32.3 & 51.7 \\
\hline & Bachelors & 16 & 29.0 & 80.7 \\
\hline & Masters & 27 & 16.1 & 96.8 \\
\hline & Doctorate & 3 & 3.2 & 100.0 \\
\hline & Total & 93 & 100.0 & \\
\hline \multirow{6}{*}{$\begin{array}{l}\text { Level at } \\
\text { Company }\end{array}$} & Management & 15 & 16.9 & 16.9 \\
\hline & Professional & 33 & 37.1 & 54.0 \\
\hline & Clerica] & 19 & 21.3 & 75.3 \\
\hline & Technical & 12 & 13.5 & 88.8 \\
\hline & Other & 10 & 11.2 & 100.0 \\
\hline & Total & 89 & 100.0 & \\
\hline \multirow{11}{*}{$\begin{array}{l}\text { Household } \\
\text { Income }\end{array}$} & $<20,000$ & 15 & 16.7 & 16.7 \\
\hline & $20-29,999$ & 12 & 13.3 & 30.0 \\
\hline & $30-39,999$ & 15 & 16.7 & 46.7 \\
\hline & $40-49,999$ & 13 & 14.4 & 61.1 \\
\hline & $50-59,999$ & 4 & 4.4 & 65.5 \\
\hline & $60-69,999$ & 6 & 6.7 & 72.2 \\
\hline & $70-79,999$ & 9 & 10.0 & 82.2 \\
\hline & $80-89,999$ & 3 & 3.3 & 85.5 \\
\hline & $90-99,999$ & 5 & 5.6 & 91.1 \\
\hline & $>100,000$ & 8 & 8.9 & 100.0 \\
\hline & Total & 90 & 100.0 & \\
\hline
\end{tabular}


Table 1

Characteristics of the Sample (cont'd)

\begin{tabular}{llcrc}
\hline Variable & & Frequency & Valid \% & Cumulative \% \\
\hline & & & & \\
& 20,000 & 33 & 36.7 & 36.7 \\
& $20-29,999$ & 33 & 36.7 & 73.4 \\
Personal & $30-39,999$ & 12 & 13.3 & 86.7 \\
Annual & $40-49,999$ & 5 & 5.6 & 92.3 \\
Income & $50-59,999$ & 2 & 2.2 & 94.5 \\
& $70-79,999$ & 2 & 2.2 & 96.7 \\
& $80-89,999$ & 1 & .0 & 96.7 \\
& $90-99,999$ & 0 & 1.1 & 97.8 \\
& $>100,000$ & 1 & 2.2 & 100.0 \\
& Total & 2 & .0 & 100.0 \\
& & 91 & 100.0 & \\
\hline
\end{tabular}

Descriptive statistics and the results of the correlation analysis are presented in Table 2. Respondents' average age in years was 40 , and average tenure with the company was 4.5 years. The mean score for organizational dissent was 60.97 (maximum $=100$ ), which indicated that the respondents as a whole were slightly inclined toward dissent. The mean score for idealism was 7.37, and the mean score for relativism was 4.80 (maximum for both $=9$ ), which implied that sample members were moderately idealistic. The mean score for corporate ethical values was 4.65 (maximum $=7$ ), and this value indicates that the environment was perceived as just slightly ethical. Overall, dissent exhibited a statistically significant negative relationship with idealism $(r=-.23, p<.05)$ and a statistically significant positive relationship with corporate ethical values $(r=$ $.22, p<.05$ ). With reference to the demographic variables, gender (being male) was negatively related to idealism $(r=-.24, p<.05)$, while minority status (being a non-white) was positively related to relativism $(r=.33, p<.01)$.

Hierarchical regression was employed to test the hypotheses of the study, and the results of the analysis are presented in Table 3 . Since various demographic factors have been found to influence ethics-related constructs (see Ford \& Richardson, 1994, for detailed summary of previous research), these factors were entered into the regression equation first as control variables. Upon entry, the demographic variables caused a marginally significant change in the model $R^{2}$ of .15 $(p<.10)$. Standardized regression coefficients indicated that education level and organizational dissent were marginally related $(\beta=.23, p<.10)$, while organizational tenure and dissent were positively related $(\beta=.28, p<.05)$. These findings support previous research that has determined that both experience and education tend to increase ethical judgments (Dawson, 1997; Glover, 
Bumpus, Logan \& Ciesla, 1997; Ford \& Richardson, 1994). The two ethical ideologies and corporate ethical values were then added to the model, which resulted in a significant change in the model $R^{2}$ of $.14(p<.05)$ and a significant overall Model $F$ of $2.88(p<.01)$. Standardized regression coefficients revealed a negative relationship between dissent and idealism $(\beta=-.24, p<.05)$ and a positive relationship between corporate ethical values and dissent $(\beta=.35, p<$ $.01)$.

Table 2

Correlation Analysis

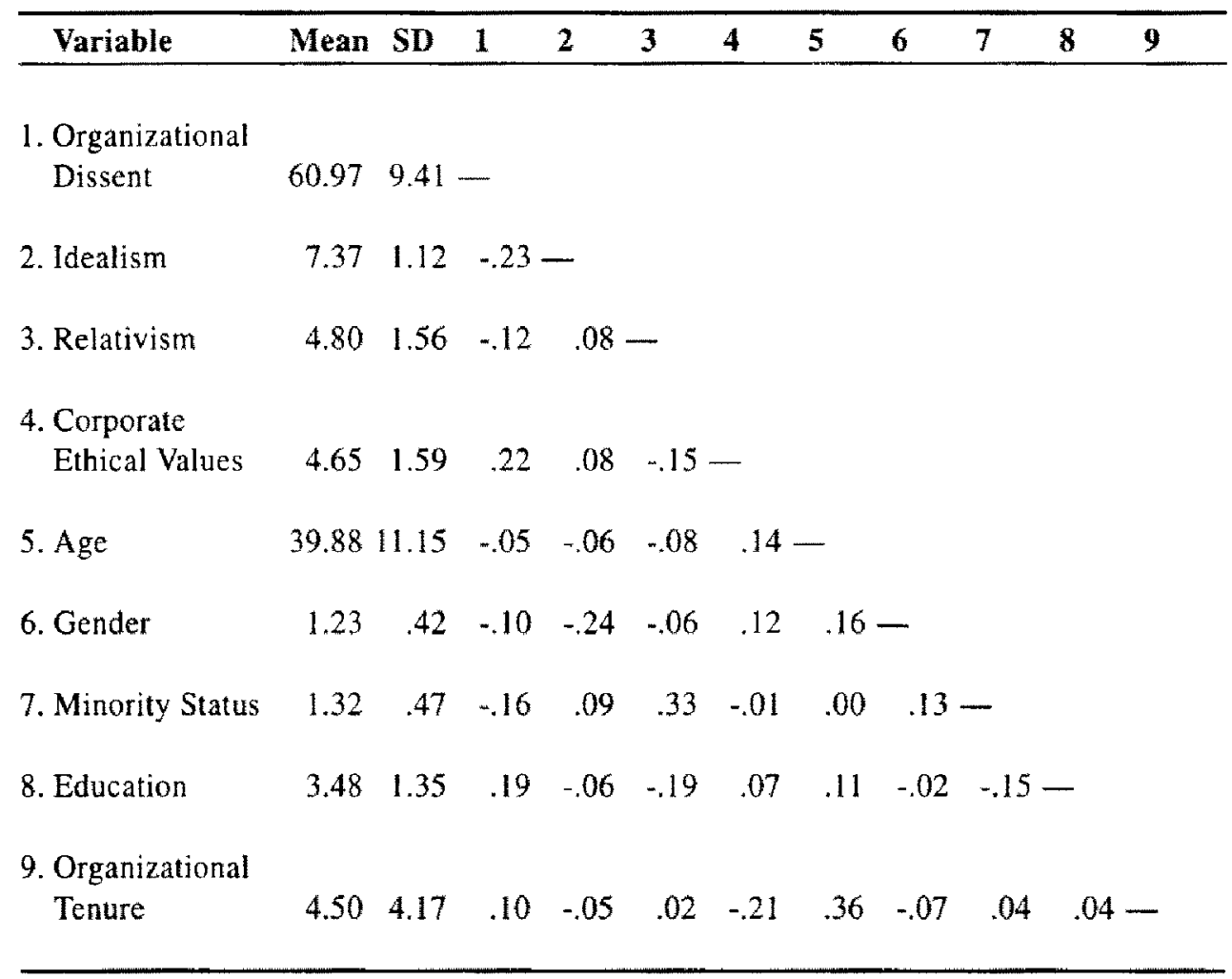

Notes: Correlations greater in magnitude than .21 are significant at the 0.05 level. Correlations greater in magnitude than .32 are significant at the 0.01 level. 
Table 3

Hierarchical Regression Analysis

\begin{tabular}{lcc}
\hline $\begin{array}{c}\text { Independent } \\
\text { Variable }\end{array}$ & $\begin{array}{c}\text { Step 1 } \\
\text { Standardized } \\
\text { Coefficients }\end{array}$ & $\begin{array}{c}\text { Step 2 } \\
\text { Standardized } \\
\text { Coefficients }\end{array}$ \\
\hline Age & -.13 & $-.21 \wedge$ \\
Gender & -.02 & -.10 \\
Minority Status & -.16 & -.13 \\
Education Level & $.23 \wedge$ & .15 \\
Organizational Tenure & $.28 *$ & $.36 * *$ \\
Idealism & & $-.24 *$ \\
Relativism & & -.01 \\
Corporate Ethical Values & & $.35 * *$ \\
Change in $R^{2}$ & .15 & .14 \\
Change in $F$ & $2.02 \wedge$ & $3.82 *$ \\
Overall $R^{2}$ & .15 & .29 \\
Overall Adjusted $R^{2}$ & .07 & .19 \\
Overall Model $F$ & $2.02 \wedge$ & $2.88 * *$ \\
\hline
\end{tabular}

$$
\begin{array}{r}
* * p<.01 \\
{ }^{*} p<.05 \\
{ }^{\wedge} p<.10
\end{array}
$$

\section{Discussion of Findings and Conclusions}

We hypothesized that organizational dissent would more likely be exhibited by individuals whose responses were consistent with having idealistic views. The results indicated that the opposite was true among the individuals in the sample, with idealism sharing a negative association with organizational dissent. Also, the hypothesis that relativism was negatively related to organizational dissent was not supported by the regression results. The hypothesis that corporate ethical values would positively influence organizational dissent was supported by the data.

Our results implied that personal moral philosophies marginally influence organizational dissent. Specifically, the findings indicated that idealistic views might limit the exhibition of dissent to superiors and to fellow employees, while relativistic views were not related to dissent. These results were unexpected given previous work in this area, but they may be accounted for in several ways. 
Since "individuals who are highly idealistic have an overriding concern for the welfare of others" (Barnett et al., 1996, p. 1163), idealists may avoid dissent because they have compassion for those involved in a questionably activity. Essentially, they may exercise tacit approval to protect the people or companies involved in the ethical dilemmas. The social practices within the organization, the quality of the supervisor-subordinate relationships, and other situational conditions present in the organization may also have caused this negative association (Kassing \& Avtgis, 1999). For example, respondents may have believed that morally questionable acts in the company did not directly harm organizational members. High scores in idealism would therefore cause individuals to accept such acts since they do not adversely affect the welfare of others. The organization's culture may have also prompted the negative relationship between idealism and dissent. Organizational culture defines generally preferred practices, and a culture that treats dissent as a behavior that adversely affects the well being of others might discourage dissent among highly idealistic individuals.

Relativism and dissent were unrelated in this study, and the variables' conceptual distinctions can be used to explain this finding. While relativism involves the degree to which individuals reject universal moral codes, dissent involves an individual's expression of disagreement about organizational practices, which would make any relationship that exists between these two variables complex and inconsistent. Both individuals who score high in relativism and individuals who score low in relativism could essentially express dissent about an unethical situation or act, but they would have different reasons for doing so. Highly relativistic employees would express dissent because they feel the circumstances of a morally questionable situation are inherently deleterious, while employees scoring low in relativism employees would express dissent because they accept the notion of universal moral principles. Clearly, additional research is needed to clarify this seemingly complicated relationship.

Corporate ethical values were found to positively influence organizational dissent in this company. The relationship between corporate ethical values and the exhibition of organizational dissent was expected and provides further support for the link between organizational culture and individual conduct. Unlike many of the personal factors that are typically beyond an organization's control, corporate cultures and ethical values can be cultivated and managed by company leaders. Consequently, managers need to support corporate ethics programs and promote their integration throughout all levels of the organization, as well as ensure "open door" policies that facilitate the expression of dissent. A relatively useful business strategy would include developing formal codes of conduct or corporate codes of ethics that provide guidance about standards of behavior. By outwardly promoting a culture of ethical sensitivity and awareness, companies may be able to systematically improve ethical decisions. 
The correlation analysis indicated that males tended to be less idealistic compared to women, and several post hoc inferences can be made. Some research illustrates that women tend to think and behave more ethically compared to men (see Ford \& Richardson, 1994), which may suggest that women are more idealistic. For instance, women have strong intentions to whistle-blow when faced with a morally questionable situation (Wise, Barnett \& Brown, 1997), and this may be caused by their concern for the well being of others. Some research also indicates that women favor relationship building, egalitarianism, and nurturing more than do men (see Valentine \& Godkin, 2000).

The correlation analysis also implied that members of minority groups tended to be more relativistic compared to Anglos. While race has not been extensively explored in the ethics literature, some differences across various racial groups have been noted. For instance, Tsalikis and Nwachukwu (1988) found black students and white students held different ethical views about price discrimination. Similarly, McCuddy and Perry (1996) found that individual perceptions of ethical standards varied across different racial groups. Relativism may indeed influence these relationships since high relativism tends to negatively influence ethical decisions.

Even though the results of this study are promising, the study had several key limitations that must be highlighted. Most notably, the sample size was relatively small, and the sample was taken from just one health care organization, which reduces the ability to externalize results and increases the probability of sample bias. For instance, there may be reason to believe that health care professionals score relatively high in idealism since many of the organizations for which they work uniquely prescribe highly constructive cultures (Peterson, Cooper \& Scherer, 2000; Seago, 2000), and these sample characteristics could have influenced the findings. Sample homogeneity may have also influenced the results of the study since women, who scored high in idealism, composed over three-quarters of the sample, and well over half of the participants were Anglos, who scored low relativism. Furthermore, the fact that the corporate ethical values construct was measured through individual perceptions must be emphasized. If these values had been measured as a singular corporate-level construct, the analysis may have provided quite different results.

Overall, the results of this study imply that dissent is influenced by both individual and organizational principles. Future studies should further clarify these relationships by obtaining much larger cross-sectional samples from a variety of organizations. Future research should also examine how both gender and race influence ethical judgments through both idealism and relativism. Such research would provide further insight into the complex nature of ethical decisions. 


\section{References}

Akaah, I. P. (1993). Organizational culture and ethical research behavior. Journal of the Academy of Marketing Science, 21 (1), 59-64.

Akaah, I. P. \& Riordan, E. A. (1990). The incidence of unethical practices in marketing research: An empirical investigation. Journal of the Academy of Marketing Science. $18,143-152$.

Ajzen, I. \& Fishbein M. (1980). Understanding attitudes and predicting social behavior. Englewood Cliffs, NJ: Prentice Hall, Inc.

Barnett, T., Bass, K. \& Brown, G. (1994). Ethical ideology and ethical judgment regarding ethical issues in business. Journal of Business Ethics, 13, 469-480.

Barnett, T., Bass, K. \& Brown, G. (1996). Religiosity, ethical ideology, and intentions to report a peer's wrong doing. Journal of Business Ethics, 15, 1161-1174.

Barnett, T., Bass, K., Brown, G. \& Herbert, F. J. (1998). Ethical ideology and the ethical judgments of marketing professionals. Journal of Business Ethics, 17, 715-723.

Brief, A. P. \& Motowidlo, S. (1986). Prosocial organizational behaviors. Academy of Management Review, 11, 710-725.

Conner, P. E. \& Becker, B. W. (1975). Values and the organization: Suggestions for research. Academy of Management Journal, 18 (3), 550-561.

Dawson, L. M. (1997). Ethical differences between men and women in the sales profession. Journal of Business Ethics, 16, 1143-1152.

Dozier, J. B. \& Miceli, M. P. (1985). Potential predictors of whistle-blowing: A prosocial behavior perspective. Academy of Management Review, 10, 823-836.

Dubinsky, A. J. \& Loken, B. (1989). Analyzing ethical decision making in marketing. Journal of Business Research, 19, 83-107.

Ford, R. C. \& Richardson, W. D. (1994). Ethical decision making: A review of the empirical literature. Journal of Business Ethics, 13, 205-221.

Forsyth, D. R. (1980). A taxonomy of ethical ideologies. Journal of Social Psychology, 39, $175-184$.

Forsyth, D. R. (1981). Moral judgment: The influence of ethical ideology. Personality and Social Psychology Bulletin. 7, 218-223.

Forsyth, D. R. (1992). Judging the morality of business practices: The influence of personal moral philosophies. Journal of Business Ethics. 11, 461-470. 
Forsyth, D. R. \& Nye, L. (1990). Personal moral philosophies and moral choice. Journal of Research in Personality, 24, 398-414.

Forsyth, D. R. \& Pope, W. R. (1984). Ethical ideology and judgments of social psychological research: A multidimensional analysis. Journal of Personality and Social Psychology, 6 (6), 1365-1375.

Gaertner, K. (1991). The effect of ethical climate on manager's decisions. In R. M. Coughlin (Ed.), Morality, rationality, and efficiency: New perspectives on socioeconomics. (pp. 211-223), Armonk, NY: M. E. Sharpe.

Glover, S. H., Bumpus, M. A., Logan, J. E. \& Ciesla, J. R. (1997). Re-examining the influences of individuals on ethical decision making. Journal of Business Ethics. 16, 1319-1329.

Haberstroh, C. \& Gerwin, D. (1972). Climate factors and the decision process, General Systems, 17, 129-141.

Hegstrom, T. G. (1995). Focus on organizational dissent. In Critical perspectives on communication research and pedagogy. (pp. 83-94), St. Inghert, Germany: Rohrig University Press.

Hunt, S. D. \& Vasquez-Parraga, A. Z. (1993). Organization consequences, marketing ethics, and salesforce supervision. Journal of Marketing Research, 30, 78-90.

Hunt, S. D. \& Vitell, S. (1986). A general theory of marketing ethics. Journal of Macromarketing, 6, 5-16.

Hunt, S. D. \& Vitell, S, (1993). The general theory of marketing ethics: A retrospective and revision. In N. C. Smith and J. A. Quelch (Eds.), Ethics in marketing. (pp. 775784), Homewood, IL: Irwin.

Hunt, S. D., Wood, V. R. \& Chonko, L. B. (1989). Corporate ethical values and organizational commitment in marketing. Journal of Marketing, 53, 79-90.

Jansen, E. \& Von Glinow, M. A. (1985). Ethical ambience and organizational reward systems. Academy of Management Review 10 (4), 814-822.

Jones, T. M. (1991). Ethical decision making by individuals in organizations: An issuecontingent model. Academy of Management Review, 16 (2), 366-395.

Kassing, J. W. (1998). Development and validation of the organizational dissent scale. Management Communication Quarterly, 12 (2), 183.

Kassing, J. W. \& Avtgis, T. A. (1999). Examining the relationship between organizational dissent and aggressive communication. Management Communication Quarterly, $13(1), 100-116$. 
Liedtka, J. (1991). Organizational value contention and managerial mindsets. Journal of Business Ethics, 10, 543-557.

McCuddy, M. K. \& Perry, B. L. (1996). Individual differences and ethical beliefs. Journal of Business Ethics, 15, 261-273.

Miceli, M. P. \& Near, J. P. (1985). Organizational dissidence: The case of whistleblowing. Journal of Business Ethics, 4, 1-16.

Near, J. P., Baucus, M. S. \& Miceli, M. P. (1993). The relationship between values and practice: Organizational climates for wrongdoing. Administration \& Society, 25 (2), 204-226.

Peterson, F. L., Cooper, R. F. \& Scherer, R. F. (2000). Organizational change: Initial results in a health care setting. Psychological Reports, 86, 608-610.

Redding, W. C. (1985). Rocking boats, blowing whistles, and teaching speech communication. Communication Education, 34, 245-258.

Schein, E. (1985). Organizational culture and leadership. San Francisco: Jossey-Bass.

Schlenker, B. R. \& Forsyth, D. R. (1977). On the ethics of psychological research. Journal of Experimental Social Psychology, 13, 369-396.

Seago, J. A. (2000). Registered nurses, unlicensed assistive personnel, and organizational culture in hospitals. Journal of Nursing Administration. 30, 278-286.

Selznick, P. (1957). Leadership in administration. Evanston, IL: Row \& Peterson.

Sims, R. L. \& Keenan, J. P. (1998). Predictors of external whistleblowing: Organizational and intrapersonal variables. Journal of Business Ethics, 17, 411-421.

Stewart, L. P. (1980). Whistle blowing: Implications for organizational communication. Journal of Communication, 30 (4), 90-101.

Stone, C. D. (1975). The culture of the corporation: Where the law ends. New York: Harper \& Row.

Tompkins, P. K. (1977). Management communication in rocket research and development. Communication Monographs, 44, 1-26.

Trevino, L. K. (1986). Ethical decision making in organizations: A person-situation interactionist model. Academy of Management Review, 11 (3), 601-617.

Trevino, L. K., Butterfield, K. D. \& McCabe, D. L. (1998). The ethical context in organizations: Influences on employee attitudes and behaviors. Business Ethics Quarterly, 8 (3), 447-476. 
Trevino, L. K. \& Victor, B. (1992). Peer reporting of unethical behavior: A social context perspective. Academy of Management Journal 35 (1), 38-64.

Trevino, L. K., Weaver, G. R., Gibson, D. G. \& Tolfler, B. L. (1999). Managing ethics and legal compliance: What works and what hurs. California Management Review. $41(2), 131-151$.

Trevino, L. K. \& Youngblood, S. A. (1990). Bad apples in bad barrels: A causal analysis of ethical decision-making behavior. Journal of Applied Psychology, 75, 378-385.

Tsalikis, J. \& Nwachukwu, O. (1988). Cross-cultural business ethics: Ethical beliefs difference between blacks and whites. Journal of Business Ethics, 7, 745-754.

Valentine, S. \& Godkin, L. (2000). Supervisor gender, leadership style, and perceived job design. Women in Management Review. 15, 117-129.

Vitell, S. J, Rallapalli, K. \& Singhapakdi, A. (1993). Marketing norms: The influence of personal moral philosophies and organizational ethical culture. Journal of the Acad: emy of Marketing Science. $21,331-337$.

Weaver, G. R., Trevino, L. K. \& Cochran, P. L. (1999). Corporate ethics programs as control systems: Influences of executive commitment and environmental factors. Academy of Management Journal, 42 (1), 41-57.

Wise, T., Barnett, T. \& Brown, G. (1997). Consequence seriousness, gender, and intentions to blow the whistle on an unethical act. Journal of Business Strategies, 14, 32 46.

Yankelovich, D. (1971). What new life styles mean to market planners. Marketing Communication. 299, 38-45. 


\section{Appendix A \\ Scale Item Examples}

\section{Organizational Dissent Scale - Kassing (1998)}

I am hesitant to raise questions or contradictory opinions in my organization.

I refuse to discuss work concerns at home.

I criticize incficiency in this organization in front of everyone.

\section{Ethical Position Questionnaire — Forsyth (1980)}

\section{Idealism}

A person should make certain that their actions never intentionally harm another even to a small degree.

Risks to another should never be tolerated, irrespective of how small the risks might be.

The existence of potential harm to others is always wrong, irrespective of the bencfits to be gained.

\section{Relativism}

There are no ethical principles that are so important that they should be part of any ethics codes.

What is ethical varies from one situation to another.

Different types of moralities cannot be compared as to "rightness".

\section{Corporate Ethical Values Scale - Hunt, Wood \& Chonko (1989)}

Managers in my company often engage in hehaviors that I consider to be unethical.

In order to succed in my company, it is often necessary to compromise one's ethics.

Top management in my company has let it be known in no uncertain terms that unethical behaviors will not be tolerated. 
Sean Valentine is Assistant Professor of Management at the University of Wyoming and has a D.B.A. from Louisiana Tech University. His research has appeared in journals such as Women in Management Review, Journal of Applied Social Psychology, Psychological Reports, Hispanic Journal of Behavioral Sciences, International Journal of Management, Health Care Management Review, and Journal of Education for Business.

Kimberly Young is an Accounting Manager at Citation-Mabry Company and M.B.A. student at Lamar University.

Lorissa Bailey is a Client Rights Officer at Life Resource Community Mental Health Center and an M.B.A. student at Lamar University.

Naser Barhoum is an M.B.A. student at Lamar University.

Stacy LaBure is a Sales Representative at Roche Labs, Inc. and an M.B.A. student at Lamar University.

Natasha Glover is an accountant at Federal Prison Industries and an M.B.A. student at Lamar University.

Peter Isaac is Owner and Director of East Texas Pathology Laboratory. He has a medical degree from the University of Michigan and an M.B.A. from Lamar University. 